\title{
EDITORIAL NOTES
}

\section{More Beneficial Changes}

Our latest preceding set of these Notes having appeared fully a year ago (Environmental Conservation, 9(3), pp. 179-80, Autumn 1982), it is high-time now to bring them up to date and record some changes which in most cases should be at least as welcome to our readers and collaborators as they are to us. Meanwhile we are happy to note that the question of blank pages has proved practically a non-issue, very few of our associates or readers having commented on it-at least to us-though this may be because they are fully accustomed to finding plentiful blank pages in other journals! It may be recalled that our Publishers prevailed in this matter, but compensated us with 8 additional pages per issue, while allowing us to add up to 12 more (always in groups of 4) on payment of a reasonable fee.

\section{Return to Former Printers}

As a major step in the effective continuation and, we hope, further evolution of our Journal and allied services, we are returning to our former Printers, the Imprimerie du Journal de Genève, 20 Rue François-Dussaud, 1211 Geneva 8, Switzerland (Tel. [022] 431940 ), as from the commencement of the present issue. This we are particularly happy to announce as it was they who helped us to launch Environmental Conservation effectively a decade ago and see it through its first five, most formative years, subsequently continuing as producers though not typesetters. It is only for the last year that the actual printing has been done elsewhere. Now, with a scientifically-trained Director and Printing Engineer, Mr Francis Pulfer, and the latest of modern equipment, they seem better-than-ever able to cope with the often exacting needs of their old client. Thus returning to both typesetting and printing in the same extensive plant nearby, we should be able to be speedy in collaborative execution and our Journal will be fully Swiss again.

\section{-but Stay with Publishers}

With this 'taking back' of the Journal, we shall be assuming again full responsibility for its printing and production-indeed for practically everything except promotion of circulation and, of course, actual subscription fulfilment and distribution. These important functions will remain in the capable hands of our Publishers, Elsevier Sequoia SA, of similarly lakeside Lausanne, who are loyally dedicated to our Journal's cause. Their address is given on the notepaper of our Journal and on the cover of every issue, and is the one to write to on all matters pertaining to circulation, subscriptions, free specimen copies, etc.

\section{Proofs of Papers and Editorial Items}

The Author (or the first-named one in cases of double or more numerous authorship) of each signed major paper or shorter item in the editorial section will be sent two sets of galley proofs of the item, one of which should be corrected meticulously and returned expeditiously to the Editor by the date filled in on the accompanying green explanatory slip headed 'Proofs' and using the sticky label provided. Otherwise the Editor reserves the right to pass the item for make-up, though there will still exist the possibility of correcting any serious error when 'revises' are checked by the Editor about a week later. Please note, however, that alterations at that stage are apt to be extremely costly - such that reimbursement may have to be sought from 'offending' Authors or their institutions.

\section{Ordering Forms and Reprinting}

With each set of proofs, sticky label for return to the Editor, and explanatory green slip, will be sent a green ordering form which should be returned to the Editor with the proofs-indicating that fifty free offprints will suffice (or, perhaps, not be wanted) and also any more that may be required. The amount involved for these extra offprints (or, alternatively, reprints with printed covers but no extraneous material) should be indicated by clearly circling it in the appropriate table of prices on the ordering form, and a cheque enclosed where possible in Swiss Francs-made out to The Foundation for Environmental Conservation, who will pay the Printers. These prices being reasonable and the free entitlement generous by most standards, no further photocopying or other reproduction can be allowed (with the exceptions indicated in the next section). Permission for reprinting, for any institutional copying in bulk, or for reproduction 'in any form or by any means' of items in the Journal, will always require the special permission of the copyrightholding Foundation for Environmental Conservation (for whom the Editor is authorized to act), and will presuppose at least due acknowledgement of the Journal and its Publishers.

\section{$S C R s, N N C s, C \& M s$, and $R \& N s$}

These four, more-or-less regular, sections of the Journal will continue in sequences of filled pages as latterly-except that, with the improved local printing facilities explained above, it should be possible (when both time and space allow) to be prompt again with rapid publication of 'stop press' items of extreme urgency.

The new set-up includes an undertaking by the Printers to send a galley proof of each signed item to its Author (or the first-named where more than one) of accepted items in all these 4 sections, together with forms for placing orders for any additional number of offprints or for any reprints that may be desired (see below). As 50 free offprints are henceforth to be sent to the first-named Author also of signed SCRs (Short Communications \& Reports), and NNCs (Notes, News \& Comments), the copyrightholder's permission for free photocopying is hereby rescinded - except in the $C \& M$ and $R \& N$ sections, where it is extended to Authors and Co-authors of their own items only.

\section{Offprints and Reprints}

Within three weeks of publication, the Printers will send to first-signing Authors of items in the Editorial section, of papers, and of SCRs and NNCs (but not C\&Ms and E\&Ns, as explained above), 50 free offprints (which may include extraneous material) of their contribution. These consignments will be by registered surface mail to the addresses given in the published versionunless another address 'for consignment' has been given on the green ordering form, or special arrangements e.g. for airmail dispatch or a changed address have been made specifically with the Printers. At the same time will be dispatched any further number of offprints (or reprints with printed covers but no extraneous material) that the Author or Authors in each case may have ordered when returning proofs and either paid for or undertaken to do so-preferably in Swiss Francs. 